\section{About now}

\author{
Stephen Hancocks OBE
}

Editor-in-Chief

About now, hundreds of mostly young people throughout the country will be preparing to start dental school. It will be an anxious and exciting time for them and their families, as for many it will be their first venture in living away from home and discovering independent life. It will also mark the beginning of their professional personas and in all probability a life-long commitment to a career in patient care of one sort or another. It is strange to think, but also reassuring, that in the fullness of time they will be the movers and innovators, the names in tomorrow's papers (in a good way) and that by 2035 or thereabouts some will be becoming the leaders of the profession, the dental politicians and editors, the professors and the consultants.

I suspect that deep in our subconscious identities our seasonal body clocks have been programmed by the academic year from a very early age. The creeping mists and mellow afternoon suns of September, the unaccustomed feel of a new school blazer, tie or blouse, the uncertainty of changed timetables, unknown places, corridors, rooms and teachers are redolent of life-phases that recur in slightly altered but repetitive guises throughout our own development as well as those of our children, grandchildren, friends and neighbours. Feelings that presage study and enterprise. Recently involved in a project associated with dental schools, I have been reminded of just how much there is to learn, what a huge volume of knowledge there is to assimilate within the curriculum and been made aware of how complex the BDS course now is. As well as the actual information to be digested there is the need to be able to understand and negotiate the technological intricacies of e-learning methods and the ever present requirement to integrate academic endeavour with dexterous skills.

\section{THE PITFALLS OF UNDERESTIMATION}

But I have fallen into the trap, by describing above how much there is to learn, of forgetting that I have not only already learnt this but have also added to that store of learning ever since qualifying. Not that I am pretending for a moment that I can remember at any given time the names, courses and branches of all the cranial nerves, nor the diameter in microns of a dentinal tubule or the chemical symbols for the polymers in used in restorative materials. But I am aware that such things exist, where to go to refresh my memory and how each of these things fit into the need to assess and treat patients; perhaps for explaining hypersensitivity, perhaps for understanding the progression of oral carcinomas. This is true of and familiar to the overwhelming majority of us, but we are in danger of neglecting the reality that we have this vast repertoire of information and the ability to make connections within it. In consequence, in taking that for granted, we risk undervaluing ourselves and forgetting as qualified dentists just who we are and what we know.

In the coming times I sense that as a profession we are going to have to become more and more proactive in defending our rights, our dignity and our professional independence, despite this having been stolen from us technically by the previous government. As part of this battle I think we will have to rekindle a sense of who we are and re-muster the significance of all that we have to offer. It is quite as easy to lose sight of these qualities as it is to forget the names of all twelve cranial nerves but we need to remind ourselves, because to refresh is also to progress and now more than ever it is imperative to do so. This might read as being somewhat alarming to our new colleagues about to step across a dental school threshold for the first time; they might wonder what type of uncertain world they are about to enter. I do not think they need to worry overtly as I suspect the prospect of the future has always held such insecurities but it is important for them, and for us, that we are as prepared as we can be for the inevitability of change and challenge and that we are not complacent about our circumstances.

At the end of the day, during the course of each day and beginning at the start of each session when the surgery door swings open to reveal the next patient we have to remember that it is 'about now'. For our patients it is about their visit, yesterday, today and tomorrow; it is to them that we give our professional dedication and it is from them that we gain our dignity and our continuing professional satisfaction. If we are to survive, actually, more correctly, as we will survive we need to remind ourselves of our skills, our value and our essential contribution to healthcare and to society. More than ever I believe that as a professional body of individuals we have to be aware, astute and 'about now'.

DOI: $10.1038 /$ sj.bdj.2010.772 